Germán Ayala Valencia*, Luci Cristina de Oliveira Vercik and Andrés Vercik

\title{
A new conductometric biosensor based on horseradish peroxidase immobilized on chitosan and chitosan/gold nanoparticle films
}

\begin{abstract}
A new conductometric biosensor was developed and characterized; the biosensor was based on horseradish peroxidase that was deposited in chitosan and chitosan/AuNPs films. The biosensors were characterized by scanning electron microscopy and current-voltage curves. Current-voltage curves in biosensors showed that the electrical conductivity and bistability in biosensors can be modulated by horseradish peroxidase. Horseradish peroxidase catalyzed the reduction of $\mathrm{H}_{2} \mathrm{O}_{2}$ to $\mathrm{H}_{2} \mathrm{O}$ with the oxidation of the prosthetic group $\left(\mathrm{Fe}^{3+}\right)$ in the enzyme to $\mathrm{Fe}^{4+}=0$. Conductometric signal in the biosensors increased with the gradual increase of $\mathrm{H}_{2} \mathrm{O}_{2}$ concentration, and it was due to the $\mathrm{H}_{2} \mathrm{O}_{2}$ reduction. Linear hydrogen peroxide detection was observed for a concentration between 0 and $15 \mathrm{~mm}$. The results proved that these biosensors could have promising industrial applications, due to its rapid and sensitive $\mathrm{H}_{2} \mathrm{O}_{2}$ detection.
\end{abstract}

Keywords: chitosan; conductometric biosensor; gold nanoparticles; horseradish peroxidase; hydrogen peroxide.

DOI 10.1515/polyeng-2014-0072

Received March 25, 2014; accepted April 22, 2014; previously published online May 20, 2014

\section{Introduction}

Hydrogen peroxide $\left(\mathrm{H}_{2} \mathrm{O}_{2}\right)$ is a by-product of several highly selective oxidases, and also, it is an essential mediator of several types of oxidative metabolism in many fields such as, food industry, pharmaceutical, environmental, biological, industry settings, clinical control, and environmental

*Corresponding author: Germán Ayala Valencia, Faculty of Animal Science and Food Engineering, Food Science Department, University of São Paulo, Pirassununga, São Paulo, Brazil; and Faculty of Animal Science and Food Engineering, Basic Sciences Department ZAB/ FZEA, University of São Paulo, São Paulo, Pirassununga, Brazil, e-mail: gayalav1230@gmail.com Luci Cristina de Oliveira Vercik and Andrés Vercik: Faculty of Animal Science and Food Engineering, Basic Sciences Department ZAB/ FZEA, University of São Paulo, São Paulo, Pirassununga, Brazil protection [1, 2]. Conventional techniques for $\mathrm{H}_{2} \mathrm{O}_{2}$ quantification, e.g., titrimetry, chemiluminescence, and spectrometry are generally time consuming, highly prone to interferences, difficult for automation detection, and the fact that they cannot be used in food or biological samples, where the samples have several compounds [1].

In recent years, a lot of investigations have been carried out on biosensors for $\mathrm{H}_{2} \mathrm{O}_{2}$ quantification [3-6], according to Malhotra et al. [7] "Biosensors are analytical devices incorporating biological materials such as enzymes, tissues, micro-organism, antibodies, cell receptors or biologically derived materials or biomimic component in intimate contact with a physic-chemical transducer or transducing microsystems". Electrochemical biosensors are rapid, selective, sensitive, and can be produced at low cost [2]; in addition, electrochemical biosensors have been demonstrated to be a simple, very efficient, and inexpensive method for $\mathrm{H}_{2} \mathrm{O}_{2}$ quantification [8].

Electrochemical biosensors can be classified as amperometric, potentiometric, and conductometric [9]; among these, the amperometric biosensor has been extensively studied due to its rapid detection, sensitivity, and selectivity [1, 2, 10-15]. However, the selectivity of the amperometric devices is only governed by the redox potential of the electroactive species present. Therefore, the current measured by the instrument can include the contributions of several chemical species [9]. Conductometric biosensors could have several advantages when compared with amperometric biosensors, e.g., easy miniaturization and large-scale production using inexpensive technology [14].

Recently, the use of chitosan and gold nanoparticles (AuNPs) to improve the stability of enzymes in biosensors has been reported $[1,16]$. In addition, chitosan has been found to be an interesting biopolymer for biosensor development due to its excellent film-forming ability, high permeability, high mechanical strength, nontoxicity, biocompatibility, and low cost [2].

The aim of this work was to study the construction of a simple conductometric biosensor to determine $\mathrm{H}_{2} \mathrm{O}_{2}$ by using horseradish peroxidase (HRP). The effect of gold nanoparticles in the electrical response of biosensors also was studied. 


\section{Materials and methods}

\subsection{Materials}

Chitosan (deacetylated grade 85\%) was obtained from Polymar (Fortaleza, Ceará, Brazil). Horseradish peroxidase type VI-A (HRP) was purchased from Sigma (Saint Louis, MO, USA). Chloroauric acid $\left(\mathrm{HAuCl}_{4}\right)$, hydrogen peroxide and other chemicals were of analytical grade and used without further purification.

\subsection{Synthesis of gold nanoparticles}

Synthesis of AuNPs was performed according to previous reports [17]. Chitosan solution $(6.92 \mathrm{mg} / \mathrm{ml})$ was prepared by dispersion of chitosan powder in $1 \%$ acetic acid at constant agitation for $30 \mathrm{~min}$. Subsequently, the solution was filtered using a vacuum and a filter paper with $14 \mu \mathrm{m}$ diameter pores. For AuNPs synthesis, $10 \mathrm{ml}$ of the chitosan solution prepared previously was mixed with $4 \mathrm{ml}$ of $\mathrm{HAuCl}_{4}(11 \mathrm{~mm})$. Synthesis of AuNPs was carried out in a water bath at $90^{\circ} \mathrm{C}$ for $3 \mathrm{~h}$.

\subsection{Films construction}

Films were prepared by casting method and using filmogenic solutions. Chitosan/AuNPs film was prepared by mixing $5 \mathrm{ml}$ of chitosan solution $(20 \mathrm{mg} / \mathrm{ml}$ ) previously dissolved in acetic acid (1\%), with $5 \mathrm{ml}$ of a colloid containing AuNPs at $11 \mathrm{~mm}$. Chitosan films without AuNPs were prepared using $10 \mathrm{ml}$ of chitosan solution $(20 \mathrm{mg} / \mathrm{ml})$ [17]. To each $10 \mathrm{ml}$ of filmogenic solution, $0.10 \mathrm{mg}$ of HRP was added and mixed for $15 \mathrm{~min}$ at room temperature in a dark room. All solutions obtained were dried at room temperature for $24 \mathrm{~h}$ in a SOLAB oven (Piracicaba, São Paulo, Brazil) [17]. Thickness determination was performed at least 10 times in each film; at least three films for each formulation were measured. The thickness was reported as average and standard error, and it was similar for all films $(2.2 \pm 0.1 \mu \mathrm{m})$.

\subsection{Enzyme activity of hydrogen peroxide immobilized in films: guaiacol test}

Chitosan, chitosan/AuNPs, chitosan/HRP, and chitosan/ AuNPs/HRP films were immersed in a solution of hydrogen peroxide $(3 \% \mathrm{v} / \mathrm{v})$; immediately, $3 \mathrm{ml}$ of guaiacol $(0.5 \%$ $\mathrm{v} / \mathrm{v}$ ) was added. The color change in the solutions was monitored visually for $5 \mathrm{~min}$. All solutions were prepared using a buffer solution ( $0.1 \mathrm{M}$ and $\mathrm{pH}=6.8)$ as solvent [18].

\subsection{Film morphology}

Surface analyses of chitosan and chitosan/AuNPs films were reported previously [17]. The surface analysis of chitosan/HRP and chitosan/AuNPs/HRP films was performed by means of a field emission scanning electron microscope (Jeol ISM 7500F, Akishima, Tokyo, Japan).

\subsection{Electrical characterization of films}

Electrical measurements of chitosan, chitosan/AuNPs, chitosan/HRP and chitosan/AuNPs/HRP films of $5 \mathrm{~mm}$ diameter were carried out using a Keithley 8009 Resistivity Test Fixture (Cleveland, OH, USA) coupled to a Keithley 2612A System SourceMeter (Cleveland, OH, USA) and using concentric electrodes (Figure 1A). Electrical measurements were carried out at room temperature. The films were stabilized by applying $0 \mathrm{~V}$ for $1 \mathrm{~min}$, followed by the application of a controlled voltage cycle consisting of a forward voltage sweep from 0 to $6 \mathrm{~V}$ and reverse voltage sweep from 6 to $0 \mathrm{~V}$. For each formulation, the films were studied at least three times.

\subsection{Electrical characterization of films: response to different concentrations of hydrogen peroxide}

Electrical response of chitosan, chitosan/AuNPs, chitosan/HRP, and chitosan/AuNPs/HRP films of $5 \mathrm{~mm}$ diameter was assessed in the same equipment (as in section 2.6) and using a conductometric cell coupled to the electrodes (Figure 1B). Initially, films were stabilized by applying $0 \mathrm{~V}$ for $1 \mathrm{~min}$; $5 \mathrm{ml}$ of buffer solution $(0.1 \mathrm{M}$ and $\mathrm{pH}=6.8$ ) was added immediately, followed by hydrogen peroxide $(3 \% \mathrm{v} / \mathrm{v})$ in several volumes to the buffer solution to achieve concentrations of hydrogen peroxide between 0 and $35 \mathrm{~mm}$. The solution was stirred by $2 \mathrm{~min}$, and then a voltage ramp between 0 to $6 \mathrm{~V}$ was applied. For each formulation, the films were studied at least three times.

\section{Results and discussion}

\subsection{Enzyme activity of hydrogen peroxide immobilized in films: guaiacol test}

Chitosan and chitosan/AuNPs films were negative to the guaiacol test (no color change). In contrast, films with 

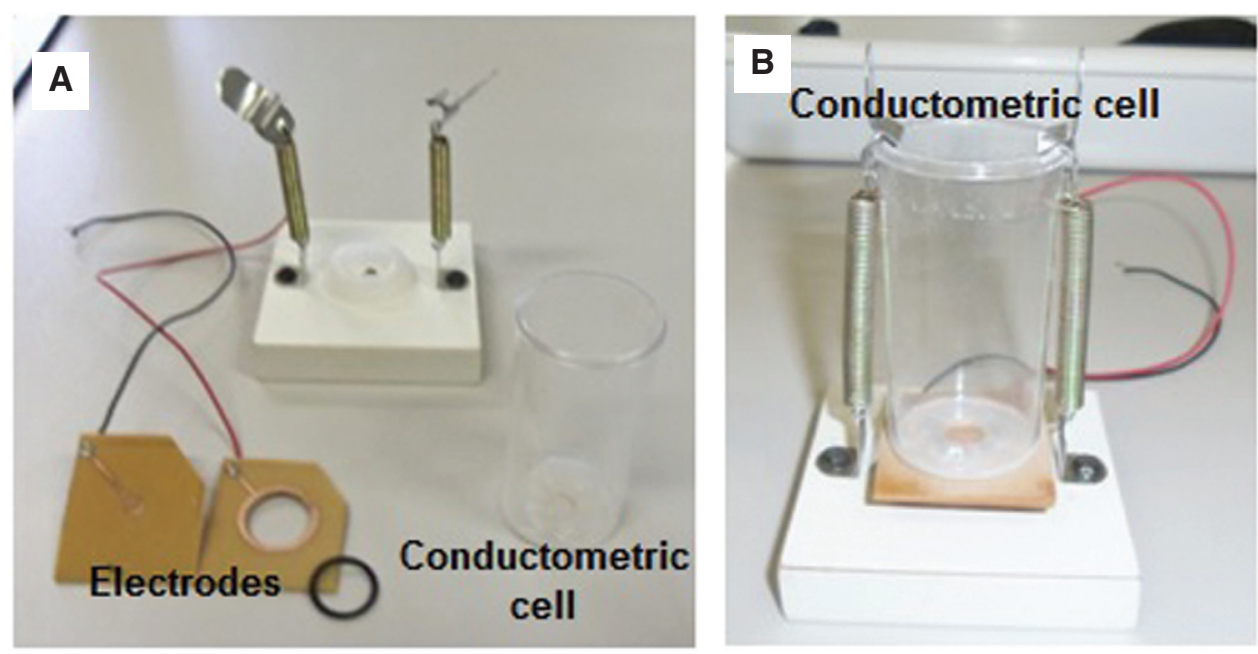

Figure 1 Illustration of the electrodes (A) and conductometric cell (B) used for the electrical analyses (photo taken by an author).

HRP were positive to the same test. The solution changed from no-color to dark yellow for chitosan/HRP film and light yellow for chitosan/AuNPs/HRP film. These results indicate that the HRP has enzymatic activity in the films [18]. Differences between color change of the chitosan/ HRP and chitosan/AuNPs/HRP films indicate that the AuNPs in films could alter the enzymatic activity of horseradish peroxidase.

\subsection{Film morphology}

Figure 2A, B shows the morphology of chitosan/HRP and chitosan/AuNPs/HRP films. Films with AuNPs exhibited a granular structure, which was different to the morphology observed for films without AuNPs; this result agrees with those reported previously for chitosan and chitosan/ AuNPs films [17]. At the surface of chitosan/HRP and chitosan/AuNPs/HRP, the HRP immobilized in the films was observed, and it showed a globular morphology revealing immobilization (Figure 2C). This image was similar to that observed by Yardimci et al. [2] for an amperometric biosensor based on HRP.

\subsection{Electrical characterization of films}

According to what was reported previously, the electrical conductivity can be modulated by the AuNP concentration; hence, the AuNPs increase the conductivity and bistability in chitosan films due to the capture of electrons in the AuNPs and its subsequent electron transfers between AuNPs [17]. A similar behavior was observed when the HRP was incorporated in films (Figure 3). This electrical behavior could be due the fact that horseradish peroxidase has as active center iron ions $\left(\mathrm{Fe}^{3+}\right)$. Iron ions could improve the trapping process, and the electrical transport could be more efficient due to the accumulation of charge in the quantum wells created by $\mathrm{Fe}^{3+}$ in HRP [17]. Hence, chitosan/HRP and chitosan/AuNPs/HRP acted as charge transport matrices that transferred the electrons from iron ions in HRP to others iron ions or to the electrodes [19].

\subsection{Electrical characterization of films: response to different concentrations of hydrogen peroxide}

The current in chitosan and chitosan/AuNPs films was not influenced by $\mathrm{H}_{2} \mathrm{O}_{2}$ concentration (Figure 4), i.e., $\mathrm{H}_{2} \mathrm{O}_{2}$ was not reduced by the contact with the polymer matrix or AuNPs. Current-voltage curves for chitosan/ HRP and chitosan/AuNPs/HRP films to successive additions of $\mathrm{H}_{2} \mathrm{O}_{2}$ are shown in Figure 5. These films show a rapid and sensitive response to the addition of $\mathrm{H}_{2} \mathrm{O}_{2}$. Upon addition of an aliquot of $\mathrm{H}_{2} \mathrm{O}_{2}$ to the conductometric cell, the reduction current increases uniformly until a stable value was reached. In comparison with films without HRP (Figure 4), the current in chitosan/ HRP and chitosan/AuNPs/HRP films increased with $\mathrm{H}_{2} \mathrm{O}_{2}$ addition; it was attributed to the reduction of hydrogen peroxide into oxygen and water by HRP. The present results reveal that the electron transfer between HRP and chitosan or chitosan/AuNPs films can be easily performed; hence, chitosan/HRP and chitosan/ 

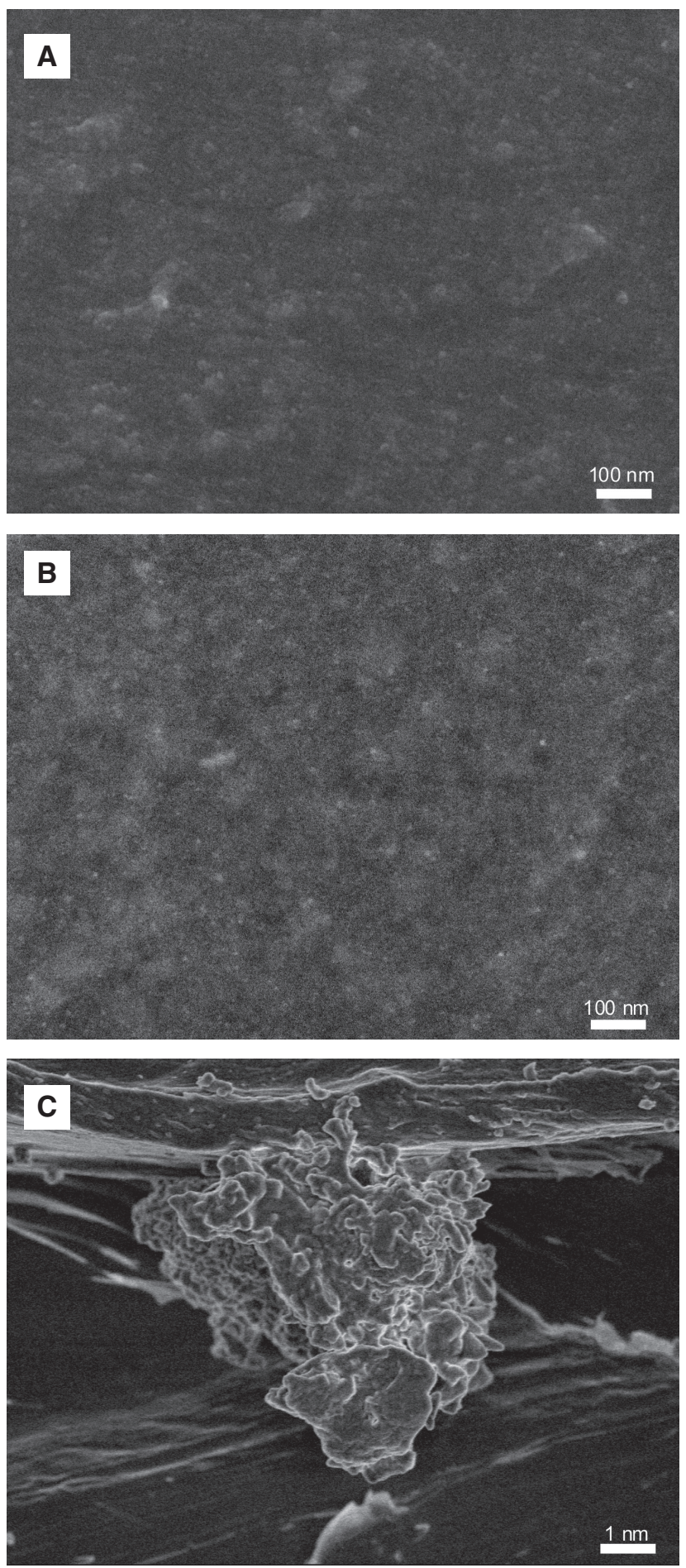

Figure 2 Scanning electron microscopy: chitosan/HRP (A, C) and chitosan/AuNPs/HRP (B) films.

AuNPs/HRP films could be used as biosensors for $\mathrm{H}_{2} \mathrm{O}_{2}$ detection.

In amperometric systems, the catalytic mechanism of HRP (with oxidation state of $\mathrm{Fe}^{3+}$ ) for reducing hydrogen peroxide is based on the oxidation of HRP to

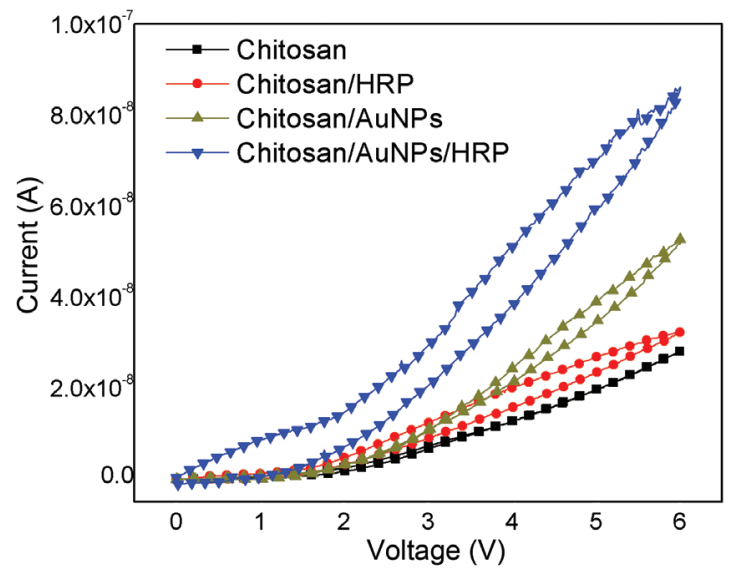

Figure 3 Current-voltage curves for the chitosan, chitosan/AuNPs, chitosan/HRP, and chitosan/AuNPs/HRP films.

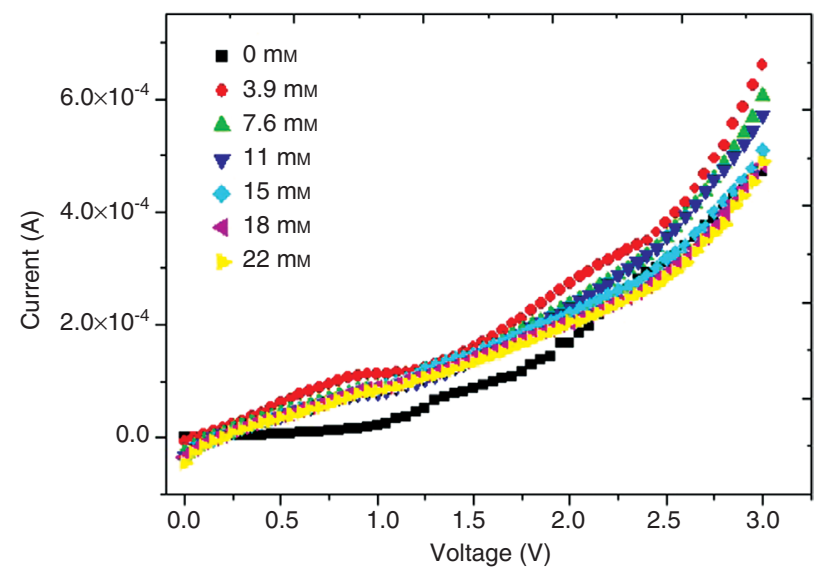

Figure 4 Current-voltage curves for the chitosan film to different $\mathrm{H}_{2} \mathrm{O}_{2}$ concentrations.

two-equivalent oxidized forms (Eqs. 1-3), called compound I (with oxidation state of $\mathrm{Fe}^{4+}=0$ ) and compound II (with oxidation state of $\mathrm{Fe}^{5+}$ ). In this process, the electrons $\left(\mathrm{e}^{-}\right)$and protons $\left(\mathrm{H}^{+}\right)$ensure the regeneration of the compound II to HRP $[12,20]$. The electron transfer in these reactions is the current that is quantified in an amperometric system [12].

$$
\mathrm{HRP}\left(\mathrm{Fe}^{3+}\right)+\mathrm{H}_{2} \mathrm{O}_{2} \rightarrow \text { Compound I }\left(\mathrm{Fe}^{4+}=\mathrm{O}\right)+\mathrm{H}_{2} \mathrm{O}
$$

Compound $\left(\mathrm{Fe}^{4+}=\mathrm{O}\right)+\mathrm{e}^{-}+\mathrm{H}^{+} \rightarrow$ Compound II $\left(\mathrm{Fe}^{5+}\right)$

$$
\text { Compound II }\left(\mathrm{Fe}^{5+}\right)+\mathrm{e}^{-}+\mathrm{H}^{+} \rightarrow \mathrm{HRP}\left(\mathrm{Fe}^{3+}\right)+\mathrm{H}_{2} \mathrm{O}
$$

In conductometric systems, the catalytic process does not have proton transfer; therefore, HRP can only oxide to 

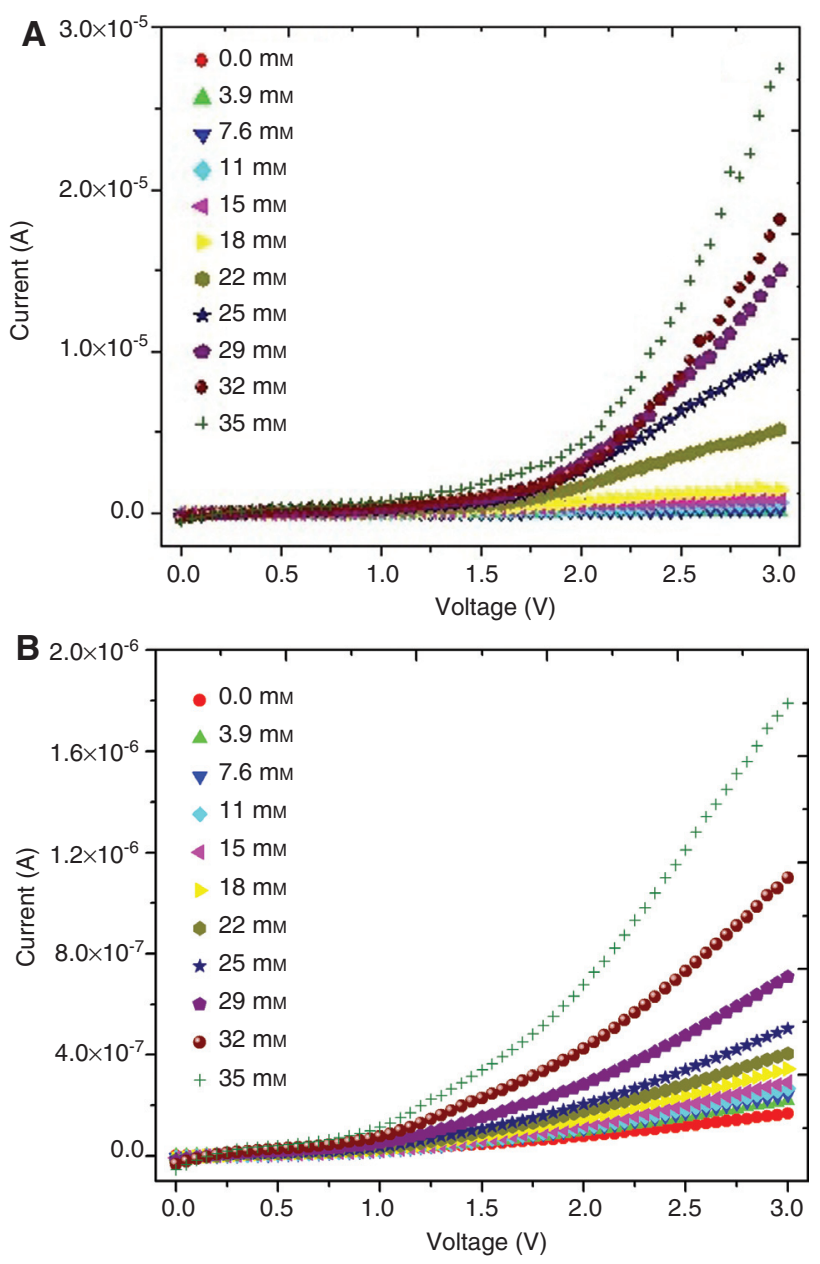

Figure 5 Current-voltage curves for the chitosan/HRP (A) and chitosan/AuNPs/HRP (B) films to different $\mathrm{H}_{2} \mathrm{O}_{2}$ concentrations.

compound I. Compound I is very unstable and can act as a transitory state where electrons move in the films, similar to that reported for AuNPs [17]. Chitosan/HRP film had a higher electrical response than the chitosan/AuNPs/HRP film probably due to the differences between oxidation states of AuNPs and the active site of HRP.

The current response and the concentration of $\mathrm{H}_{2} \mathrm{O}_{2}$ have a polynomial relationship within the concentration range between 0 and $35 \mathrm{~mm}$; the values of these parameters were calculated by nonlinear regression $\left(\mathrm{R}^{2} \geq 0.95\right)$ and are reported in Table 1 . To $1 \mathrm{~V}$ and for a $\mathrm{H}_{2} \mathrm{O}_{2}$ concentration range between 0 and $15 \mathrm{~mm}$, the biosensors have a linear response, such as $I=3 \mathrm{E}-5 \mathrm{C}-5 \mathrm{E}-5$ and $I=3 \mathrm{E}-6 \mathrm{C}-8 \mathrm{E}-8$, for chitosan/HRP and chitosan/ AuNPs/HRP, respectively. Both fits have an $R^{2}=0.94$. Linear relationships between current-concentration are very important to develop biosensors with linear calibration $[10,16]$.

\section{Conclusions}

In this paper, a new conductometric hydrogen peroxide biosensor was constructed and characterized. Horseradish peroxidase was successfully immobilized in chitosan and chitosan/AuNPs films; these biosensors showed a rapid, sensitive, and linear response to different hydrogen peroxide concentrations. Hence, HRP immobilized in chitosan and chitosan/AuNPs films could be used as biosensors and could have promising industrial applications.

Acknowledgments: The authors gratefully acknowledge the financial support from FAPESP (Fundação de Apoio à Pesquisa do Estado de São Paulo), grant number 2010/50424-3. Field emission scanning electron micrographs were provided by the IQ-UNESP.

Table 1 Current $(I)$ fit as function of $\mathrm{H}_{2} \mathrm{O}_{2}$ concentration $(C)$ to the mathematical model: $I=\mathrm{a} C^{3}+\mathrm{b} C^{2}+\mathrm{c} C+\mathrm{d}$ for three different voltages.

\begin{tabular}{|c|c|c|c|c|c|c|}
\hline \multirow[t]{2}{*}{ Film } & \multirow[t]{2}{*}{ Voltage (V) } & & & \multicolumn{2}{|c|}{ Polynomial parameters } & \multirow[t]{2}{*}{$\mathbf{R}^{2}$} \\
\hline & & a & b & c & d & \\
\hline \multirow[t]{3}{*}{ Chitosan/HRP } & 1 & $3.0 \mathrm{E}-2 \pm 1.0 \mathrm{E}-3$ & $-7.0 \mathrm{E}-4 \pm 0.5 \mathrm{E}-4$ & $5.0 \mathrm{E}-6 \pm 5.4 \mathrm{E}-8$ & $3.0 \mathrm{E}-8 \pm 1.1 \mathrm{E}-8$ & $0.97-0.99$ \\
\hline & 2 & $-9.2 \mathrm{E}-2 \pm 0.8 \mathrm{E}-3$ & $8.4 \mathrm{E}-3 \pm 1.3 \mathrm{E}-3$ & $-8.0 \mathrm{E}-5 \pm 2.6 \mathrm{E}-7$ & $2.0 \mathrm{E}-7 \pm 5.4 \mathrm{E}-8$ & 0.95 \\
\hline & 3 & $7.4 \mathrm{E}-1 \pm 1.4 \mathrm{E}-2$ & $-2.9 \mathrm{E}-3 \pm 0.8 \mathrm{E}-3$ & $-8.0 \mathrm{E}-5 \pm 1.1 \mathrm{E}-6$ & $4.0 \mathrm{E}-7 \pm 4.2 \mathrm{E}-8$ & $0.98-0.99$ \\
\hline \multirow[t]{3}{*}{ Chitosan/AuNP/HRP } & 1 & $6.4 \mathrm{E}-3 \pm 1.8 \mathrm{E}-3$ & $-2.0 \mathrm{E}-4 \pm 1.7 \mathrm{E}-3$ & $1.0 \mathrm{E}-6 \pm 1.9 \mathrm{E}-7$ & $2.0 \mathrm{E}-8 \pm 0.7 \mathrm{E}-8$ & 0.99 \\
\hline & 2 & 4.4E-2 $2 \pm 1 \mathrm{E}-3$ & $-1.6 \mathrm{E}-3 \pm 3.4 \mathrm{E}-4$ & $2.0 \mathrm{E}-5 \pm 4.8 \mathrm{E}-6$ & $6.0 \mathrm{E}-8 \pm 1.4 \mathrm{E}-8$ & $0.97-0.99$ \\
\hline & 3 & $1.2 \mathrm{E}-1 \pm 2.0 \mathrm{E}-2$ & $-4.4 \mathrm{E}-3 \pm 0.3 \mathrm{E}-3$ & $5.0 \mathrm{E}-5 \pm 3.2 \mathrm{E}-7$ & $1.0 \mathrm{E}-8 \pm 3.2 \mathrm{E}-9$ & $0.97-0.99$ \\
\hline
\end{tabular}

All values were expressed as mean \pm standard error $(n=3)$. 


\section{References}

[1] Kang XB, Pang GC, Liang XY, Wang M, Liu J, Zhu W. Electrochim. Acta 2012, 62, 327-334.

[2] Yardimci FS, Senel M, Baykal A. Mater. Sci. Eng. C 2012, 32, 269-275.

[3] Schmidt TF, Caseli L, dos Santos Jr DS, Oliveira Jr ON. Mater. Sci. Eng. C 2009, 29, 1889-1892.

[4] Tang J, Wang BQ, Wu ZY, Han XJ, Dong SJ, Wang EK. Biosens. Bioelectron. 2003, 18, 867-872.

[5] Miao Y, Tan SN. Anal. Chim. Acta 2001, 437, 87-93.

[6] Wang G, Xu JJ, Chen HY, Lu ZH. Biosens. Bioelectron. 2003, 18, 335-343.

[7] Malhotra B, Singhal R, Chaubey A, Sharma SK, Kumar A. Recent Trends Biosens. 2005, 5, 92-97.

[8] Wei N, Xin X, Du JY, Li JL. Biosens. Bioelectron. 2011, 26, 3602-3607.

[9] Mello LD, Kubota LT. Food Chem. 2002, 77, 237-256.
[10] Lei CX, Hu SQ, Gao N, Shen GL, Yu RQ. Bioelectrochemistry 2004, 65, 33-39.

[11] Krajewska B. Enzyme Microb. Technol. 2004, 35, 126-139.

[12] Lu X, Zhang Q, Zhang L, Li J. Electrochem. Commun. 2006, 8, 874-878.

[13] Lin J, Qu W, Zhang S. Anal. Biochem. 2007, 360, 288-293.

[14] Zazoua A, Hnaien M, Cosnier S, Renault J, Kherrat R. Mater. Sci. Eng. C 2009, 29, 1919-1922.

[15] Jin X, Xi F, Deshui LV, Lin X. Carbohydr. Polym. 2011, 85, 786-791.

[16] Luo XL, Xu JJ, Zhang Q, Yang GJ, Chen HY. Biosens. Bioelectron. 2005, 21, 190-196.

[17] Valencia GA, Llanos JHR, Vercik LCO, Vercik A. J. Polym. Eng. 2014, 34, 105-111.

[18] Zeraik AE, Souza FSA, Fatibello-Filho O. Quim. Nova 2008, 31, 731-734.

[19] Willner B, Katz E, Willner I. Current Opin. Biotechnol. 2006, 17, 589-596.

[20] Veitch NC. Phytochemistry 2004, 65, 249-259. 